\title{
Novel treatments for inflammatory bowel disease
}

\author{
Hyo Sun Lee ${ }^{\star}$, Soo-Kyung Park ${ }^{\star}$, and Dong Il Park
}

Division of Gastroenterology, Department of Internal Medicine, Kangbuk Samsung Hospital, Sungkyunkwan University School of Medicine, Seoul, Korea

Received: November 28, 2017

Accepted: December 4, 2017

\section{Correspondence to}

Dong Il Park, M.D.

Division of Gastroenterology, Department of Internal Medicine and Gastrointestinal Cancer, Kangbuk Samsung Hospital, Sungkyunkwan University School of Medicine, 29 Saemunan-ro, Jongno-gu, Seoul 03181, Korea

Tel: +82-2-2001-8555

Fax: $+82-2-2001-8360$

E-mail:diksmc.park@samsung.com

*These authors contributed equally to this work.

This paper was contributed by Korean Association for the Study of Intestinal Diseases.
Increased understanding of the immunopathology of inflammatory bowel disease (IBD) has led to the development of targeted therapies and has unlocked a new era in IBD treatment. The development of treatment options aimed at a variety of pathological mechanisms offers new hope for customized therapies. Beyond anti-tumor necrosis factor agents, selective lymphocyte trafficking inhibitors have been proposed as potent drugs for IBD. Among these, vedolizumab has recently been approved for both Crohn's disease and ulcerative colitis. Numerous other agents for IBD treatment are currently under investigation, including Janus kinase inhibitors, anti-mucosal vascular addressin cell adhesion molecule-1 agents, an anti-SMAD7 antisense oligonucleotide, an anti-interleukin-12/23 monoclonal antibody, and a sphingosine-1-phosphate receptor-1 selective agonist. These agents will likely expand the treatment options available for the management of IBD patients in the future. In this review, we discuss the efficacy and safety of novel agents currently under investigation in IBD clinical trials.

Keywords: Inflammatory bowel diseases; Janus kinase inhibitors; Anti-mucosal vascular addressin cell adhesion molecule-1 agent; Anti-SMAD7 antisense oligonucleotide; Anti-interleukin-12/23

\section{INTRODUCTION}

Inflammatory bowel diseases (IBD), including ulcerative colitis (UC) and Crohn's disease (CD), are chronic, disabling, and progressive disorders characterized by lifelong treatment and whose incidences are increasing in Asia [1-4]. For several decades, medical treatments for IBD were limited to non-biological therapies (i.e., aminosalicylates, thiopurines, and steroids), which provide symptomatic improvement but do not change the disease course [5]. With the advances in the understanding of the pathological mechanisms involved in IBD, new therapies have been proposed, with the most important development being the introduction of anti-tumor necrosis factor (TNF) agents [6,7]. Anti-TNF agents (infliximab, adalimumab, and certolizumab) have reduced the need for surgery and hospitalization and have improved the quality of life of patients by changing the course of the disease $[8,9]$. Thus, guidelines recommend the use of anti-TNF agents initially in moderate-to-severe IBD or if non-biological therapy fails [10-13]. However, these treatments have not been effective in all patients, and patients who initially responded to treatment have also lost their responsiveness over time [14-17]. Furthermore, although anti-TNF agents are generally well tolerated, their use is associated with adverse effects, including 
risks of infection and malignancies [18-21]. For these reasons, several studies investigating new therapies have been conducted, and some novel drugs have shown potentially favorable clinical effects in IBD trials. Novel therapies include selective lymphocyte trafficking inhibitors (vedolizumab and etrolizumab), an anti-mucosal vascular addressin cell adhesion molecule-1 (anti-MAdCAM-1; PF-00547659) agent, Janus kinase inhibitors (JAK inhibitor; tofacifinib), anti-SMAD7 antisense oligonucleotide (mongersen), anti-interleukin (IL)-12/23 (ustekinumab), and the sphingosine-1-phosphate receptor-1 $(\mathrm{S} 1 \mathrm{Pl}$ ) selective agonist (ozanimod). This review article discusses the characteristics, indications, efficacy and safety of these novel therapies.

\section{RECOMMENDATIONS}

\section{Novel biologic agents}

\section{Anti-adhesion molecules}

IBD consists of a chronic inflammation of the gastrointestinal tract that occurs when inflammatory mediators migrate to target organs. It is characterized by lymphocyte infiltration of the intestinal lamina propria and the process of lymphocyte migration in IBD is regulated by the interaction of several integrins with tissue specific adhesion molecules [22]. Therefore, therapies targeting lymphocyte adhesion and trafficking have been developed and have emerged as novel treatment options for IBD.

\section{Natalizumab}

Natalizumab is an anti- $\alpha_{4}$ integrin antibody that was demonstrated to induce and maintain remission in patients with CD [23]. This agent is not selective for the gastrointestinal system; it not only interferes with integrin $\alpha \beta_{7}$ associated with MAdCAM-1 expressed in the gut epithelium, but it also interferes with the integrin $\alpha_{4} \beta_{1}$ associated with the vascular cell adhesion molecule 1 expressed on the epithelium of inflammatory tissues [24]. Natalizumab interferes with lymphocyte accumulation in the intestinal mucosa and induces improvement in intestinal inflammation. However, progressive multifocal leukoencephalopathy (PML) due to John Cunningham virus reactivation was reported in natalizum- ab-treated patients and the use of this agent has been largely reduced [25]. Natalizumab was temporarily withdrawn from the market but was re-introduced in 2006 in the United States only for patients not suitable for other immunomodulator therapy [26].

\section{Vedolizumab}

Vedolizumab is an anti- $\alpha_{4} \beta_{7}$ integrin antibody that blocks the interaction between $a_{4} \beta_{7}$ integrin and MAdCAM-1. Vedolizumab also reduced the risk of systemic side effects such as the PML observed with natalizum$\mathrm{ab}$ treatment by acting selectively in the intestine. In randomized placebo-controlled trials, vedolizumab demonstrated effectiveness for induction and maintenance of clinical response in both UC and CD. In the induction therapy trial of the GEMINI I study, 374 patients with moderate-to-severe UC patients were randomized to receive $300 \mathrm{mg}$ of vedolizumab intravenously or placebo at weeks $o$ and 2 and disease was evaluated at week $6[27]$. The clinical response rates at 6 weeks were $47.1 \%$ and $25.5 \%(p<0.001)$, clinical remissions were $16.9 \%$ and $5.4 \%(p=0.001)$, and mucosal healing was observed in $40.9 \%$ and $24.8 \%(p=0.001)$, respectively for patients in the vedolizumab-treated and placebo groups. Patients who had a response to vedolizumab at 6 weeks were included in the maintenance therapy trial. A total 373 patients were randomly assigned to receive vedolizumab $300 \mathrm{mg}$ or placebo every 4 or 8 weeks and disease was evaluated at week 52 . The clinical remission rates were $44.8 \%$ in the every 4 -week dosing group, $41.8 \%$ in the every 8 -week dosing group, and $15.9 \%$ in the placebo group $(p<0.001)$. Moreover, the rate of mucosal healing and steroid-free remission was significantly higher in patients treated with vedolizumab compared to placebo.

The GEMINI II study, having the same study design as the GEMINI I study, included patients with moderate-to-severe $\mathrm{CD}$ and evaluated the efficacy of vedolizumab in the induction and maintenance of remission [28]. In the induction trial, clinical remission (defined as Crohn's Disease Activity Index [CDAI $\leq 150$ ) occurred in $14.5 \%$ of the vedolizumab-treated group and in $6.8 \%$ of the placebo-treated group $(p=0.02)$ at week 6 . However, there was no statistically significant difference in clinical response ( $\geq 100$-point decrease in the CDAI score) between the two groups at week 6 . In the maintenance trial, clinical remission occurred in $36.4 \%$ and 
$39 \%$ of patients receiving vedolizumab every 4 weeks $(p=$ $0.0042)$ and every 8 weeks $(p=0.0007)$ compared to $21.6 \%$ in those who received placebo at week 52 . The GEMINI III study evaluated the safety and efficacy of vedolizum$\mathrm{ab}$ for remission induction in patients with $\mathrm{CD}$ in which treatment with the anti-TNF agent failed [29]. At week 6, the difference in clinical remission (CDAI $\leq 150)$ between the vedolizumab-treated group and the placebo group was not statistically significant ( $15.2 \%$ and $12.1 \%$, respectively; $p=0.433$ ). However, at week 10, clinical remission was seen in $26.6 \%$ of the vedolizumab-treated group versus $12.1 \%$ of the placebo group ( $p=0.001$ ); furthermore, therapeutic benefits of vedolizumab in patients who had previously failed anti-TNF therapy were also observed [29]. Vedolizumab was administered to over 3,000 patients with UC or CD, with no evidence of PML occurrence and had generally a safe profile [30]. Two recent interim reports from the ongoing GEMINI long-term safety phase III extension trial of vedolizumab on UC and CD also supported the safety of vedolizumab [31,32]. Vedolizumab was approved by the U.S. Food and Drug Administration (FDA) and the European Medicines Agency (EMA) in patients with severe UC or CD who do not respond to conventional or anti-TNF therapy.

\section{Etrolizumab}

Etrolizumab is monoclonal antibody directed against the $\beta 7$ subunit of the $a_{4} \beta_{7}$ and $a E \beta_{7}$ integrins that inhibits the binding of the $\beta_{7}$ integrin to MAdCAM-1 and E-cadherin [33]. The EUCALYPTUS study is a placebo-controlled, randomized phase II study that evaluated the efficacy of etrolizumab in 124 patients with active UC [34]. Patients were randomly assigned to receive etrolizumab $100 \mathrm{mg}$ at weeks $\mathrm{O}, 4$, and 8; etrolizumab at a $420 \mathrm{mg}$ loading dose at week o and then $300 \mathrm{mg}$ at weeks 2, 4, and 8; or matching placebo. At week 10, clinical remission (defined as Mayo Clinic Score $\leq 2$, no subscore > 1 ) rates were $21 \%$ in the etrolizumab $100 \mathrm{mg}$ group $(p=0.004), 10 \%$ in the etrolizumab $300 \mathrm{mg}$ group $(p=0.048)$, compared to none in the placebo group. Mild and moderate adverse events occurred at a similar rate in all study groups. A phase III trial to confirm these promising results is in progress.

PF-00547659

PF-00547659 is a monoclonal antibody directed against the gut-specific endothelial adhesion molecule MAdCAM-1. In an initial randomized, double-blind placebo-controlled phase I study, 8o patients with active UC were randomized to receive single or multiple doses 3 doses 4 weeks apart) of 0.03 to $10 \mathrm{mg} / \mathrm{kg}$ of PF-00547659 or placebo given intravenously or subcutaneously [35]. Although clinical response and remission rates were not significantly higher in the PF-00547659-treated group than in the placebo group, no apparent drug-related adverse events were observed. Based on these results, phase II studies were conducted in UC and CD patients. In the TURANDOT study (NCTo1620255), 357 patients with moderate-to-severe UC were randomized to receive 7.5, 22.5, and $75 \mathrm{mg}$ of PF-00547659 or placebo. At week 12, clinical remission rates were $11 \%, 17 \%$, and $16 \%$ for $7.5,22.5$, and $75 \mathrm{mg}$, respectively, versus $3 \%$ in the placebo group $(p<0.05)$ [36]. In contrast, the OPERA study (NCT01276509) evaluating moderate-to-severe CD patients did not demonstrate any benefits of treatment because of a high placebo response [37]. Adverse event rates were similar between the therapy and placebo group and no episodes of serious infection or of PML were observed. Several clinical trials have been conducted on the efficacy and safety of PF-00547659 and future phase III trials are scheduled.

\section{Blockage of downstream signaling}

Orally administered small molecule inhibitors act by interfering with intracellular signaling and have many advantages compared to therapeutic antibodies, such as reduced production costs and oral administration. One of the most advanced drugs is the JAK inhibitor tofacitinib, which has already been approved for the treatment of rheumatoid arthritis in the United States.

\section{Tofacitinib}

Tofacitinib is an oral JAK inhibitor that mainly inhibits the JAK1 and JAK3 isoforms and blocks the downstream effects of a large subset of proinflammatory cytokines including IL-2, IL-3, IL-4, IL-5, IL-6, IL-12, IL-15, IL-21, and interferon- $\gamma$. JAK-dependent intracellular signaling pathways are involved in the pathophysiology of many chronic inflammatory diseases, including rheumatoid arthritis and IBD [38,39]. Tofacitinib has been shown to be effective in a phase II trial in 194 patients with moderate to severe active UC [40]. At week 8, clinical re- 
sponses occurred in 32\%, 48\%, 61\%, and $78 \%$ of patients receiving tofacitinib at a dose of $0.5 \mathrm{mg}(p=0.39), 3 \mathrm{mg}(p$ $=0.55), 10 \mathrm{mg}(p=0.10)$, and $15 \mathrm{mg}(p<0.001)$, respectively, versus $42 \%$ of patients in the placebo group. Clinical remission at week 8 was observed in $33 \%, 48 \%$, and $41 \%$ of patients receiving tofacitinib at a dose of 3,10 , and $15 \mathrm{mg}$, respectively, versus $10 \%$ of patients in the placebo group $(p<0.05)$. Although the overall drug safety profile was acceptable, dose-dependent elevation of lowand high-density lipoproteins was reported in patients treated with tofacitinib. In the phase III study, patients with active UC were assigned to receive tofacitinib $10 \mathrm{mg}$ twice daily or placebo for 8 weeks [41]. At week 8, significantly more patients in the tofacitinib-treated group achieved remission $(p<0.01$ and $p<0.001$, respectively), mucosal healing ( $p<0.001$ for both), and clinical response $(p<0.001$ for both) versus placebo. Adverse event rates were similar between the groups and rates of serious cases were not higher with tofacitinib. Tofacitinib was also evaluated in patients with moderate-to-severe active CD $[42,43]$. In the previous phase II trial after a 4-week induction therapy, tofacitinib failed to show any significant clinical response. However, this study might have limitations such as the short duration of study, small sample size, and high placebo response rate (47\%). In a repeat phase IIb study that complemented these limitations, clinical remission at 8 weeks was observed in $44 \%$ and $43 \%$ of patients receiving tofacitinib twice daily at a dose of 5 and $10 \mathrm{mg}$, respectively, versus $37 \%$ for the placebo group. Similar findings were observed in the TNF inhibitor-experienced patients with tofacitinib $10 \mathrm{mg}$ twice daily [44]. In addition, a 26-week maintenance study in patients with 128 clinical responses or clinical remissions subsequent to the induction study was conducted. The proportion of patients with clinical response or remission at week 26 was not significant because rates were $40 \%$ and $56 \%$ for 5 or $10 \mathrm{mg}$ of tofacitinib twice daily versus $38 \%$ for placebo [42]. Other JAK inhibitors are currently under clinical investigation in phase II for both UC and CD.

\section{Mongersen}

Transforming growth factor $\beta 1$ (TGF- $\beta 1$ ) is a pleiotropic cytokine that has anti-inflammatory properties and is important for cell homeostasis. In CD patients, defective TGF- $\beta 1$ activity is often observed, due to increased lev- els of SMAD7, an intracellular protein that binds to the TGF- $\beta 1$ receptor preventing downstream TGF- $\beta 1$-driven signaling [45]. Therefore, manipulation of TGF- $\beta_{1}$ signaling represents a potential therapy for IBD [46]. The safety and efficacy of mongersen, an orally administered $\mathrm{SMAD}_{7}$ antisense oligonucleotide, were studied in a multicenter, double-blind, placebo-controlled phase II trial [47]. A total of 166 patients with moderate-to-severe $\mathrm{CD}$ were randomized to receive one of three doses of mongersen (10, 40, or $160 \mathrm{mg} /$ day) or placebo for 2 weeks. The proportions of patients meeting the primary end point (CDAI $<150$ on day 15 and maintenance of this score up to day 28 ) were $55 \%$ and $65 \%$ for the 40 and $160 \mathrm{mg} /$ day groups, respectively, versus $10 \%$ in the placebo group $(p<0.001)$. The clinical response rate was significantly higher in patients receiving $10 \mathrm{mg}(37 \%), 40$ $\mathrm{mg}(58 \%)$, or $160 \mathrm{mg}(72 \%)$ mongersen compared to the placebo group (17\%) $(p=0.04, p<0.001$, and $p<0.001$, respectively). Most adverse events were related to $\mathrm{CD}$ symptoms and complications. Currently, two phase III studies for induction and maintenance therapy of patients with active CD and a phase II study for efficacy and safety of mongersen in patients with active UC are currently in progress.

\section{Blockade of proinflammatory cytokines}

\section{Ustekinumab}

IL-12 and IL-23 are proinflammatory cytokines that share a common subunit (p4o). Ustekinumab is a monoclonal IgGi antibody targeting the p4O subunit of IL12 and IL-23, and has been shown to be effective in the treatment of psoriatic arthritis and psoriasis $[48,49]$. The efficacy of ustekinumab in the induction of remission in 104 patients with moderate-to-severe CD was evaluated in a double-blind placebo-controlled study [50]. Clinical response rates for groups given ustekinumab and placebo were $53 \%$ and $30 \%(p=0.02)$, respectively, at weeks 4 and 6 , and $49 \%$ and $40 \%(p=0.34)$, respectively at week 8. Of interest, better results were observed in patients previously given infliximab. In a phase IIb study, the efficacy of ustekinumab in the induction and maintenance of remission in patients with moderate-to-severe CD refractory to anti-TNF agents was subsequently evaluated [51]. At week 6 , the clinical response was significantly increased in the ustekinumab group, while no 
Table 1. Novel treatment agents for inflammatory bowel disease

\begin{tabular}{|c|c|c|c|c|}
\hline \multirow{2}{*}{ Drug } & \multirow{2}{*}{ Type } & \multirow{2}{*}{ Target } & \multicolumn{2}{|c|}{ Clinical status } \\
\hline & & & Crohn's disease & Ulcerative colitis \\
\hline \multicolumn{5}{|c|}{ Anti-adhesion molecules } \\
\hline Vedolizumab & Monoclonal $\mathrm{Ab}$ & $\alpha_{4} \beta_{7}$ Integrin & Approved & Approved \\
\hline Etrolizumab & Monoclonal Ab & $\beta_{7}$ Integrin & - & Phase III \\
\hline Natalizumab & Monoclonal Ab & $\alpha_{4}$ Integrin & Approved & - \\
\hline PF-00547659 & Monoclonal Ab & MadCAM-1 & Phase II & Phase II \\
\hline \multicolumn{5}{|c|}{ Blockade of the downstream signalling pathways } \\
\hline Tofacitinib & Small molecule & $\mathrm{JAK}_{1} / \mathrm{JAK}_{3}$ & Phase III & Phase III \\
\hline Mongersen & Antisense oligonucleotide & $\mathrm{SMAD}_{7}$ & Phase II & - \\
\hline \multicolumn{5}{|c|}{ Blockade of proinflammatory cytokines } \\
\hline Ustekinumab & Monoclonal Ab & IL-12/IL-23 (p40) & Approved & - \\
\hline \multicolumn{5}{|l|}{ Others } \\
\hline Ozanimod & Small molecule & $\mathrm{S}_{1} \mathrm{P}_{1}$ & Phase II & Phase III \\
\hline
\end{tabular}

Adapted from Narula et al. [54], with permission from Nature Publishing Group.

$\mathrm{Ab}$, antibody; MadCAM, mucosal vascular addressin cell adhesion molecule-1; JAK, Janus kinase; IL, interleukin; SıP1, sphingosine-1-phosphate receptor-1.

difference in clinical remission was observed. Although the primary endpoint was set at 6 weeks, both the response and remission rates were higher at 8 weeks than at 6 weeks. These results suggest that the mechanism of action ustekinumab has a slow onset, and that week 6 is perhaps too early to assess the clinical response. At week 22, patients with an initial response to ustekinumab had a significantly increased clinical response and clinical remission rate with ustekinumab as maintenance therapy. Several adverse effects have been reported, but these were similar to the adverse effects reported in the placebo group in clinical trial for CD. Ustekinumab has recently been approved by the both the U.S. FDA and the EMA for the treatment of patients with CD. Phase III trials of ustekinumab for the treatment of CD and UC are currently underway [52].

\section{Other agents}

\section{RPC1063}

Ozanimod (RPC1063) is a novel oral small molecule immunomodulatory agonist mainly for the $\mathrm{S} 1 \mathrm{P} 1$ receptors. Ozanimod induces peripheral lymphocyte sequestration, decreasing the number of activated lymphocytes circulating to the gastrointestinal tract [53]. The first phase II study, the TOUCHSTONE study, evaluated the induction and maintenance treatment of ozanimod in 197 patients with moderate to severe UC [41]. At week 8, $16 \%$, and $57 \%$ of patients receiving ozanimod $1 \mathrm{mg}$ daily, achieved clinical remission and clinical response as compared with $6 \%$ and $37 \%$ of the placebo group, respectively. At week 32, the rates of clinical remission were $21 \%$ and $26 \%$ in patients that had received 1 and 0.5 mg of ozanimod, respectively, and $6 \%$ in in the placebo-treated group, while the clinical response rates were $51 \%, 35 \%$, and $20 \%$, respectively. The overall drug safety profile was good and the most common adverse events were anemia and headache. Ozanimod has currently entered phase III studies on induction and maintenance therapy for UC, and a phase II study on induction therapy of ozanimod in CD is currently ongoing.

\section{CONCLUSIONS}

Many novel therapies for IBD are under development. Some of these drugs have recently been approved for IBD treatment, but other drugs have begun to be marketed as indications for other diseases, while their efficacy in IBD is continuing to be explored. Table 1 summarizes the therapies discussed in this paper and the respective phases of development [54]. The emergence of 
new biological agents targeting specific pathways in IBD has led to a variety of novel treatments and opportunities for more individualized therapy for IBD patients. In the future, studies on the efficacy and safety of combination therapy of biological agents and other novel agents are needed, and studies on various biomarkers that may predict responses to biological drugs for IBD should be conducted.

\section{Conflict of interest}

No potential conflict of interest relevant to this article was reported.

\section{Acknowledgments}

This study was supported by a National Research Foundation (NRF) grant funded by the Korea government (NRF-2017R1A2B2009569).

\section{REFERENCES}

1. Ng SC, Shi HY, Hamidi N, et al. Worldwide incidence and prevalence of inflammatory bowel disease in the 21st century: a systematic review of population-based studies. Lancet 2017;390:2769-2778.

2. Ng WK, Wong SH, Ng SC. Changing epidemiological trends of inflammatory bowel disease in Asia. Intest Res 2016;14:111-119.

3. Singh P, Ananthakrishnan A, Ahuja V. Pivot to Asia: inflammatory bowel disease burden. Intest Res 2017;15:138141.

4. Lee KM, Lee JM. Crohn's disease in Korea: past, present, and future. Korean J Intern Med 2014;29:558-570.

5. Burger D, Travis S. Conventional medical management of inflammatory bowel disease. Gastroenterology 2011;140:1827-1837.

6. Hanauer SB, Feagan BG, Lichtenstein GR, et al. Maintenance infliximab for Crohn's disease: the ACCENT I randomised trial. Lancet 2002;359:1541-1549.

7. Sandborn WJ, van Assche G, Reinisch W, et al. Adalimum$\mathrm{ab}$ induces and maintains clinical remission in patients with moderate-to-severe ulcerative colitis. Gastroenterology 2012;142:257-265.

8. Sokol H, Seksik P, Cosnes J. Complications and surgery in the inflammatory bowel diseases biological era. Curr Opin Gastroenterol 2014;30:378-384.
9. Kim NH, Jung YS, Moon CM, et al. Long-term clinical outcomes of Korean patient with Crohn's disease following early use of infliximab. Intest Res 2014;12:281-286.

10. Choi CH, Moon W, Kim YS, et al. Second Korean guidelines for the management of ulcerative colitis. Intest Res 2017;15:7-37.

11. Park JJ, Yang SK, Ye BD, et al. Second Korean guidelines for the management of Crohn's disease. Intest Res 2017;15:38-67.

12. Harbord M, Eliakim R, Bettenworth D, et al. Third European evidence-based consensus on diagnosis and management of ulcerative colitis. Part 2: current management. J Crohns Colitis 2017;11:769-784.

13. Gomollon F, Dignass A, Annese V, et al. 3rd European evidence-based consensus on the diagnosis and management of Crohn's disease 2016: Part 1: diagnosis and medical management. J Crohns Colitis 2017;11:3-25.

14. Allez M, Karmiris K, Louis E, et al. Report of the ECCO pathogenesis workshop on anti-TNF therapy failures in inflammatory bowel diseases: definitions, frequency and pharmacological aspects. J Crohns Colitis 2010;4:355-366.

15. Ben-Horin S, Chowers Y. Review article: loss of response to anti-TNF treatments in Crohn's disease. Aliment Pharmacol Ther 2011;33:987-995.

16. Seo HI, Park DI, Kim TO, et al. The effect of infliximab on patients with ulcerative colitis in Korea. Intest Res 2014;12:214-220.

17. Lin WC, Chou JW, Yen HH, et al. Outcomes of limited period of adalimumab treatment in moderate to severe Crohn's disease patients: Taiwan Society of Inflammatory Bowel Disease Study. Intest Res 2017;15:487-494.

18. Ford AC, Peyrin-Biroulet L. Opportunistic infections with anti-tumor necrosis factor- $\alpha$ therapy in inflammatory bowel disease: meta-analysis of randomized controlled trials. Am J Gastroenterol 2013;108:1268-1276.

19. Walsh AJ, Weltman M, Burger D, et al. Implementing guidelines on the prevention of opportunistic infections in inflammatory bowel disease. J Crohns Colitis 2013;7:e449-e456.

20. Lee JW, Choi CH, Park JH, et al. Clinical features of active tuberculosis that developed during anti-tumor necrosis factor therapy in patients with inflammatory bowel disease. Intest Res 2016;14:146-151.

21. Chung KB, Lee EY, Im JP, Han SK, Yim JJ. Clinical characteristics and treatment responses of patients who developed tuberculosis following use of a tumor necrosis 
factor- $\alpha$ inhibitor. Korean J Intern Med 2013;28:174-179.

22. Lobaton T, Vermeire S, Van Assche G, Rutgeerts P. Review article: anti-adhesion therapies for inflammatory bowel disease. Aliment Pharmacol Ther 2014;39:579-594.

23. Sandborn WJ, Colombel JF, Enns R, et al. Natalizumab induction and maintenance therapy for Crohn's disease. N Engl J Med 2005;353:1912-1925.

24. Villablanca EJ, Cassani B, von Andrian UH, Mora JR. Blocking lymphocyte localization to the gastrointestinal mucosa as a therapeutic strategy for inflammatory bowel diseases. Gastroenterology 2011;140:1776-1784.

25. Bloomgren G, Richman S, Hotermans C, et al. Risk of natalizumab-associated progressive multifocal leukoencephalopathy. N Engl J Med 2012;366:1870-1880.

26. Lowenberg M, D'Haens G. Next-generation therapeutics for IBD. Curr Gastroenterol Rep 2015;17:21.

27. Feagan BG, Rutgeerts P, Sands BE, et al. Vedolizumab as induction and maintenance therapy for ulcerative colitis. N Engl J Med 2013;369:699-710.

28. Sandborn WJ, Feagan BG, Rutgeerts P, et al. Vedolizumab as induction and maintenance therapy for Crohn's disease. N Engl J Med 2013;369:711-721.

29. Sands BE, Feagan BG, Rutgeerts P, et al. Effects of vedolizumab induction therapy for patients with Crohn's disease in whom tumor necrosis factor antagonist treatment failed. Gastroenterology 2014;147:618-627.

30. Colombel JF, Sands BE, Rutgeerts P, et al. The safety of vedolizumab for ulcerative colitis and Crohn's disease. Gut 2017;66:839-851.

31. Vermeire S, Loftus EV Jr, Colombel JF, et al. Long-term efficacy of vedolizumab for Crohn's disease. J Crohns Colitis 2017;11:412-424.

32. Loftus EV Jr, Colombel JF, Feagan BG, et al. Long-term efficacy of vedolizumab for ulcerative colitis. J Crohns Colitis 2017;11:400-411.

33. Cepek KL, Parker CM, Madara JL, Brenner MB. Integrin alpha E beta 7 mediates adhesion of T lymphocytes to epithelial cells. J Immunol 1993;150(8 Pt 1):3459-3470.

34. Vermeire S, O’Byrne S, Keir M, et al. Etrolizumab as induction therapy for ulcerative colitis: a randomised, controlled, phase 2 trial. Lancet 2014;384:309-318.

35. Vermeire S, Ghosh S, Panes J, et al. The mucosal addressin cell adhesion molecule antibody PF-00547,659 in ulcerative colitis: a randomised study. Gut 2011;60:10681075 .

36. Vermeire S, Sandborn WJ, Danese S, et al. Anti-MAdCAM antibody (PF-00547659) for ulcerative colitis (TURANDOT): a phase 2, randomised, double-blind, placebo-controlled trial. Lancet 2017;390:135-144.

37. D'Haens G, Lee S, Tarabar D, et al. OPo22 Anti-MAdCAM-1 antibody (PF-00547659) for active refractory Crohn's disease: results of the OPERA study. 1oth Congress of European Crohn's and Colitis Organisation (ECCO); 2015 Feb 18-21; Barcelona, ES. Vienna (AT): ECCO, 2015: S14.

38. Lundquist LM, Cole SW, Sikes ML. Efficacy and safety of tofacitinib for treatment of rheumatoid arthritis. World J Orthop 2014;5:504-511.

39. Vijayakrishnan L, Venkataramanan R, Gulati P. Treating inflammation with the Janus kinase inhibitor CP-690,550. Trends Pharmacol Sci 2011;32:25-34.

40. Sandborn WJ, Ghosh S, Panes J, et al. Tofacitinib, an oral Janus kinase inhibitor, in active ulcerative colitis. N Engl J Med 2012;367:616-624.

41. Sandborn WJ, Feagan BG, Wolf DC, et al. Ozanimod induction and maintenance treatment for ulcerative colitis. N Engl J Med 2016;374:1754-1762.

42. D'Haens GR, Panaccione R, Higgins P, et al. 856 Efficacy and safety of oral tofacitinib for maintenance therapy in patients with moderate to severe Crohn's disease: results of a phase $2 \mathrm{~B}$ randomized placebo-controlled trial. Gastroenterology 2016;150(4 Suppl 1):S183.

43. Sandborn WJ, Ghosh S, Panes J, et al. A phase 2 study of tofacitinib, an oral Janus kinase inhibitor, in patients with Crohn's disease. Clin Gastroenterol Hepatol 2014;12:14851493.

44. Panes J, Sandborn W, Schreiber S, et al. 855 Efficacy and safety of tofacitinib for oral induction therapy in patients with moderate to severe Crohn's disease: results of a phase $2 \mathrm{~B}$ randomized placebo-controlled trial. Gastroenterology 2016;150(4 Suppl 1):S182-S183.

45. Di Sabatino A, Jackson CL, Pickard KM, et al. Transforming growth factor beta signalling and matrix metalloproteinases in the mucosa overlying Crohn's disease strictures. Gut 2009;58:777-789.

46. Marafini I, Zorzi F, Codazza S, Pallone F, Monteleone G. TGF-beta signaling manipulation as potential therapy for IBD. Curr Drug Targets 2013;14:1400-1404.

47. Kennedy BW. Mongersen, an oral $\mathrm{SMAD}_{7}$ antisense oligonucleotide, and Crohn's disease. N Engl J Med 2015;372:2461.

48. Leonardi CL, Kimball AB, Papp KA, et al. Efficacy and 
safety of ustekinumab, a human interleukin-12/23 monoclonal antibody, in patients with psoriasis: 76 -week results from a randomised, double-blind, placebo-controlled trial (PHOENIX 1). Lancet 2008;371:1665-1674.

49. Papp KA, Langley RG, Lebwohl M, et al. Efficacy and safety of ustekinumab, a human interleukin-12/23 monoclonal antibody, in patients with psoriasis: 52 -week results from a randomised, double-blind, placebo-controlled trial (PHOENIX 2). Lancet 2008;371:1675-1684.

50. Sandborn WJ, Feagan BG, Fedorak RN, et al. A randomized trial of ustekinumab, a human interleukin-12/23 monoclonal antibody, in patients with moderate-to-severe Crohn's disease. Gastroenterology 2008;135:1130-1141.
51. Sandborn WJ, Gasink C, Gao LL, et al. Ustekinumab induction and maintenance therapy in refractory Crohn's disease. N Engl J Med 2012;367:1519-1528.

52. Hibi T, Imai Y, Murata Y, Matsushima N, Zheng R, Gasink C. Efficacy and safety of ustekinumab in Japanese patients with moderately to severely active Crohn's disease: a subpopulation analysis of phase 3 induction and maintenance studies. Intest Res 2017;15:475-486.

53. Sanchez T, Hla T. Structural and functional characteristics of S1P receptors. J Cell Biochem 2004;92:913-922.

54. Narula N, Rubin DT, Sands BE. Novel therapies in inflammatory bowel disease: an evaluation of the evidence. Am J Gastroenterol Suppl 2016;3:38-44. 